\title{
Thermal and Mechanical Analysis of Silver/Carbon Nanoparticle-PMMA Nanocomposites Obtained by Miniemulsion Polymerization
}

\author{
By E. Armando Zaragoza-Contreras, ${ }^{*}$ Claudia A. Hernández-EsCobar, Mónica E. Mendoza-DuARTE, \\ Sergio G. FLORES-GALLARDO, Rigoberto IBARRA-GÓMEZ, and Alfredo MÁRQUEZ-LUCERO
}

Silver/carbon nanoparticle-poly(methyl methacrylate) nanocomposites were obtained by in situ miniemulsion polymerization. It was found by electron microscopy that nanoparticles did not disperse individually but as aggregates; however, notable increments in glass transition temperature in the order of 5 to $15^{\circ} \mathrm{C}$, determined by differential scanning calorimetry, were registered by the addition of small amounts of the nanofiller $(0.025,0.050$ or $0.10 \mathrm{wt} \%)$. Dynamic mechanical analysis indicated gains in mechanical properties, which were related to nanoparticle/polymer interfacial interaction. Results also suggested that dispersion efficiency was a determining aspect in mechanical and thermal performance.

KEY WORDS: Glass Transition / Mechanical Properties / Miniemulsion Polymerization / Nanocomposites / Nanoparticles /

It is well known that common fillers or reinforcement agents, such as calcium carbonate, carbon black, graphite, silica, natural fibers, etc., are frequently used to improve dimensional stability of polymers. However, the main effect of filler incorporation in a plastic matrix is a modulus increment, whereas a $T_{\mathrm{g}}$ increase, if occurs, is reached at very high concentrations of rigid particles. ${ }^{1-5}$ In this sense, the employment of nanofillers has proved, according to several coincident works, a strong influence on the increment of $T_{\mathrm{g}}$ and diverse mechanical properties; i.e., Okamoto et al. ${ }^{6}$ found increments in $57 \%$ and 34\%, for PMMA and PS, respectively, by the incorporation of smectic clay to form an intercalate nanocomposite. Qu et al. ${ }^{7}$ found that the addition of $1 \mathrm{wt} \%$ of montmorillonite increased the $T_{\mathrm{g}}$ of PMMA up to $10^{\circ} \mathrm{C}$.

Concerning the incorporation of nanometric variations of carbon in polymeric matrixes, a number of articles have referred the characterization of nanocomposites based on carbon nanotubes as the reinforcer. This kind of carbon presents the advantage of large aspect ratio and inherent large surface area due to its nanometric size. Evidence of strong reinforcement effect and $T_{\mathrm{g}}$ increment was reported by López Manchado et al. ${ }^{8}$ Similarly, Gong et al. ${ }^{9}$ reported large increments in modulus for poly(methyl methacrylate) at low frequencies in dynamic analysis employing single wall carbon nanotubes; a fundamental factor for the achievement of such result was the formation of nanotubes network at a very low concentration, as low as 0.39 weight percent (wt \%). More recently, Zaragoza-Contreras et al. ${ }^{10}$ reported improvements of $T_{\mathrm{g}}$ and storage modulus in PMMA by adding small amounts of multi-walled carbon nanotubes $(0.04-0.16 \mathrm{wt} \%)$; such improvements were attributed to strong surface interaction nanotube/matrix and to nanotube exfoliation.
In the present study silver/carbon nanoparticles $(\mathrm{Ag} / \mathrm{C})$ of $9 \mathrm{~nm}$ were added as the reinforcing material to poly(methyl methacrylate) (PMMA). The relevant goal was to achieve nanocomposites with significant physical changes at very low filler concentrations, in contrast with traditional composites or even nanocomposites in which different nanometric materials have been employed, as mentioned above.

\section{EXPERIMENTAL}

\section{Materials}

Methylmethacrylate (MMA) monomer (Aldrich Co.) was distilled under vacuum before polymerization; initiator 2,2'azobisisobutironitrile (AIBN) (Aldrich Co.) was recrystalized from methanol and kept at $5{ }^{\circ} \mathrm{C}$ until its usage; surfactants sodium dodecylsulfate (SDS) (Aldrich Co.) and hexadecane (HD) (Aldrich Co.) were used as delivered. Tridistilled water quality. The silver/carbon $(\mathrm{Ag} / \mathrm{C})$ nanoparticles, of $9 \mathrm{~nm}$ in diameter, were provided by Nanotechnologies Inc.

\section{Miniemulsion Polymerization}

The nanoestructured latexes were obtained under the following conditions: $60^{\circ} \mathrm{C}$ of temperature of polymerization, $300 \mathrm{rpm}$ of mechanical agitation and nitrogen atmosphere. The polymerization procedure was as follows: first, sodium dodecylsulfate (SDS, $0.2 \mathrm{~g}$ ) and tridistilled water $(80 \mathrm{~g})$ were loaded to a glass flask; this mixture was stirred for $15 \mathrm{~min}$ in order to allow the surfactant to stabilize in the water. Next, $\mathrm{Ag} / \mathrm{C}$ nanoparticles $(0.0250 .05$ or $0.10 \mathrm{wt} \%)$, hexadecane $(0.8 \mathrm{~g})$ and methylmethacrylate monomer $(20.0 \mathrm{~g})$ were loaded in a second glass recipient; this mixture was homogenized for $15 \mathrm{~min}$ by sonication (2510 BRANSON ultrasonic with output of $42 \mathrm{khz} \pm 6 \%$ ). Afterwards, the dispersion of nanoparticles 
was transferred to the water-surfactant solution to complete the system. To obtain stable miniemulsions $45 \mathrm{~min}$ of sonication were needed. Finally, azobisisobutironitrile $(0.1 \mathrm{~g})$ was fed to the miniemulsion $3 \mathrm{~min}$ before completing the sonication period. Once the miniemulsion was stabilized, the reactor was immersed in a bath tempered at $60^{\circ} \mathrm{C}$; this moment was considered the beginning of the polymerization, since the initiator (AIBN) was already in the system. A blank of pure PMMA was obtained under the same condition for comparison purposes. All polymerizations were allowed for $180 \mathrm{~min}$.

\section{Electron Microscopy}

Microscopy studies of the $\mathrm{Ag} / \mathrm{C}$ nanoparticles were performed in a Jeol JEM-2200 FS+CS field emission electron microscope at $200 \mathrm{KV}$. Complementarily, the $\mathrm{Ag} / \mathrm{C}$ nanoparticle-PMMA nanocomposites were characterized by using a Jeol JSM-7401F field emission electron microscope at $30 \mathrm{KV}$, with STEM mode.

\section{Differential Scanning Calorimetry (DSC)}

The $T_{\mathrm{g}}$ of the Ag/C-PMMA nanocomposites was evaluated by DSC; a blank of pure PMMA obtained under the same conditions as the nanoestructured latexes was also analyzed. DSC thermograms were run in a TA Instruments Thermal Analyst 2100. All samples were firstly heated from room temperature to $180^{\circ} \mathrm{C}$, to eliminate thermal effects fixed during the polymerization, then cooled to $40^{\circ} \mathrm{C}$ and heated again to $220^{\circ} \mathrm{C}$. $T_{\mathrm{g}}$ values were taken from the second heating process. The samples were run under air atmosphere and a heating speed of $10^{\circ} \mathrm{C} / \mathrm{min}$.

\section{Dynamical Mechanical Analysis (DMA)}

Samples for DMA were prepared as follow: first, latex samples (nanocomposite and blank) were dried in an oven at $100{ }^{\circ} \mathrm{C}$ for $24 \mathrm{~h}$; next, probes of $5 \mathrm{~cm} \times 0.2 \mathrm{~mm} \times 1 \mathrm{~cm}$ were prepared by compression at $200^{\circ} \mathrm{C}$. The analyzer employed was a TA Instruments RSA III, in which a temperature sweep was carried out from $40{ }^{\circ} \mathrm{C}$ to $200^{\circ} \mathrm{C}$, at fixed frequency and strain of $1 \mathrm{~Hz}$ and $0.1 \mathrm{~mm}$, respectively.

\section{RESULTS AND DISCUSSION}

\section{Microscopy}

HRTEM micrographs of a sample of $\mathrm{Ag} / \mathrm{C}$ nanoparticles are shown in Figure 1. It is appreciated that the $\mathrm{Ag}$ nanoparticles are perfectly separated one from each other, and that presented high polydispersity; their size comprised diameter from 50 to $5 \mathrm{~nm}$, with an average diameter, more or less, of $9 \mathrm{~nm}$ (according to supplier specification), Figure 1a. It is important to note that the Ag nanoparticles are surrounded by graphitic carbon layers and agglutinated by amorphous carbon, which protect them from agglomeration. It is possible also to observe that these particles are actually polygonal; however, for practical purposes they can be considered as spherical. A number of those particles are defect free; however, there are also numerous particles showing crystal twins as illustrated on

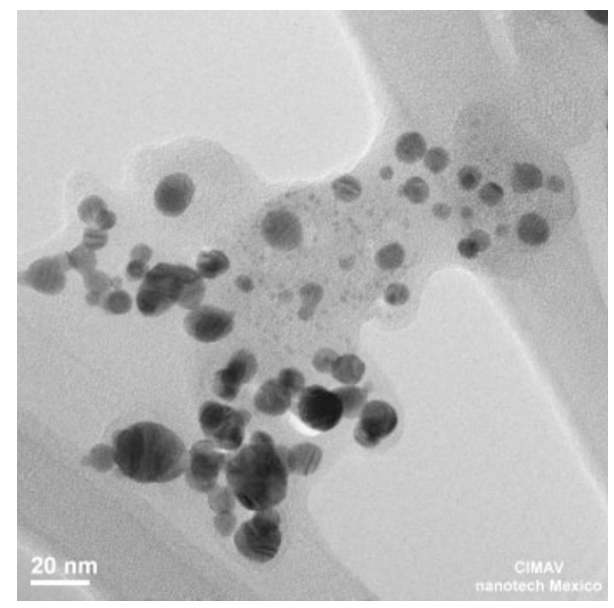

(a)

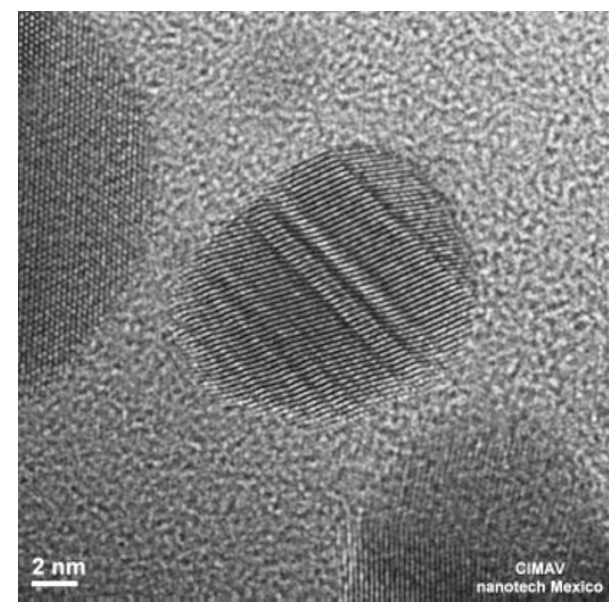

(b)

Figure 1. HRTEM micrographs of a sample of $\mathrm{Ag} / \mathrm{C}$ nanoparticles: a) Cluster of nanoparticles and b) magnification of a silver nanoparticle.

Figure $1 \mathrm{~b}$. Those defects are irrelevant for the purposes of the present work but can be interesting in other applications; i.e., in memory shape alloys.

Colloidal stability is of prime importance in miniemulsion polymerization and there is a lot of work reported about this aspect. ${ }^{11-14}$ In this research stability was taken in terms of time, thus steady polymerizations were those stable during the whole process of polymerization (about $180 \mathrm{~min}$ ). Figure 2 shows STEM micrographs of the composite particles Ag/C-PMMA with the three nanofiller concentrations $(0.025,0.05,0.10$ wt \%). First of all it was observed that the polymer particles either with or without $\mathrm{Ag} / \mathrm{C}$ nanoparticles collapsed due to the incidence of the electrons beam, even though the microscope was adjusted to the lowest power $(30 \mathrm{KV})$. It was found that with the increment of $\mathrm{Ag} / \mathrm{C}$ nanoparticle concentration a higher population of polymer particles with the inclusion of nanofiller was observed; it was also evident in all cases that the nanoparticles were not dispersed individually, as it was expected, but as particle agglomerations. 


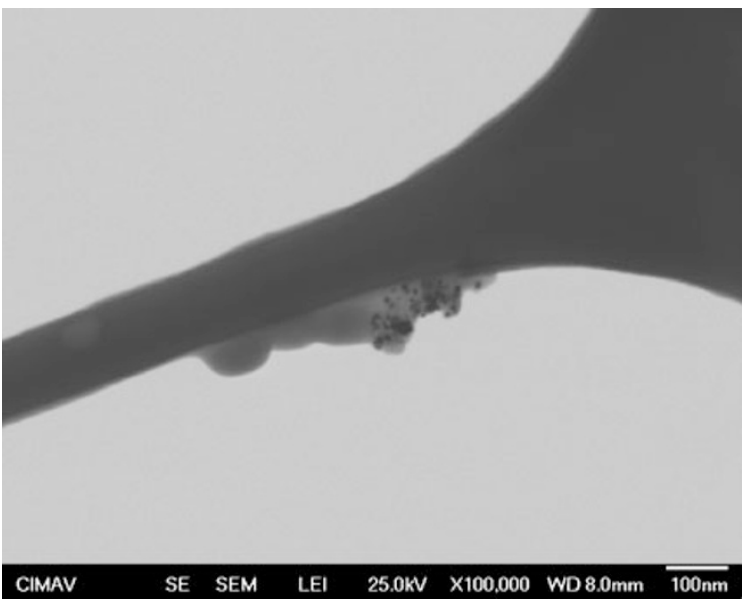

(a)

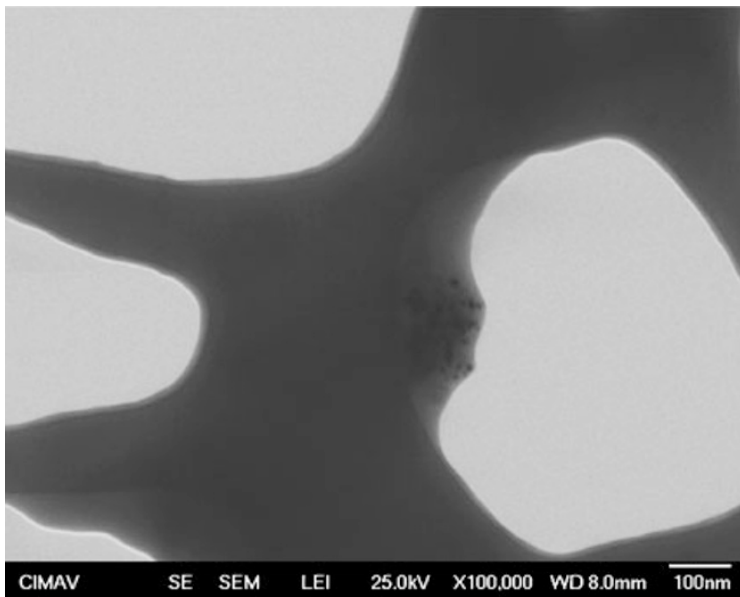

(b)

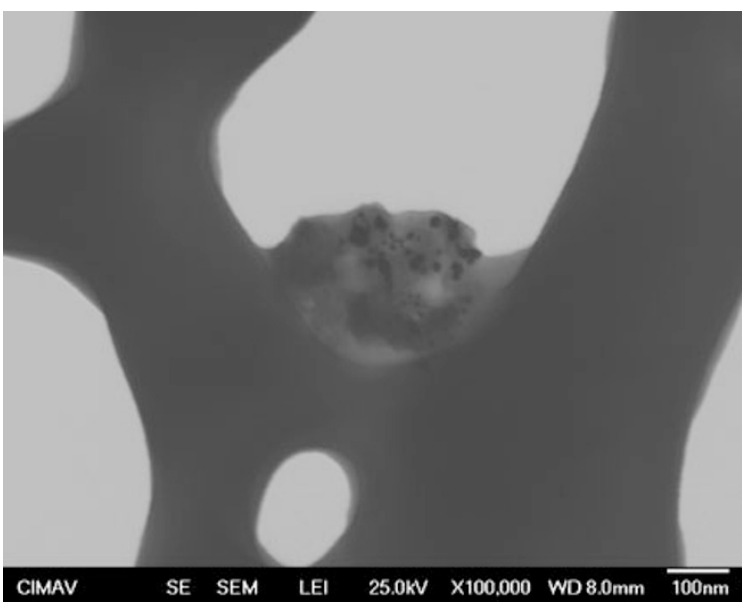

(c)

Figure 2. STEM micrographs of $\mathrm{Ag} / \mathrm{C}$ nanoparticle-PMMA nanocomposites with a) 0.025 wt $\%$, b) 0.05 wt $\%$ and c) 0.10 wt $\%$.

In Figure 3 it is shown the elemental analysis (by EDX) of a sample with the highest concentration of nanofiller. This analysis clearly indicated the presence of silver in the
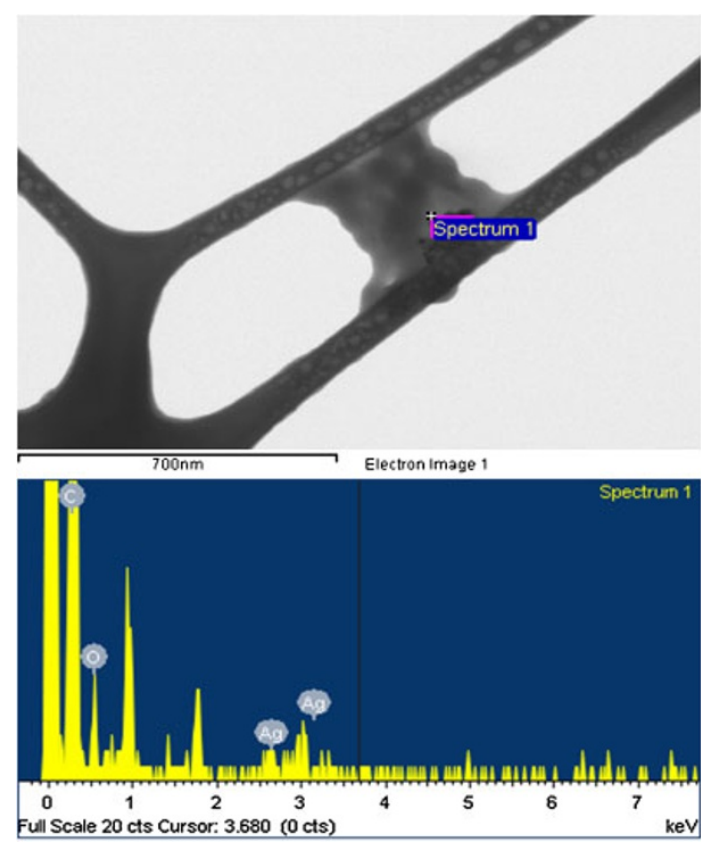

Figure 3. EDX analysis of a sample with 0.10 wt $\%$ of nanofiller.

agglomerations assumed as $\mathrm{Ag} / \mathrm{C}$ nanoparticles in the previous figure. Thus, even though the formation of heterogeneous composite latexes; that is, systems with two populations of polymer particles, one with and one without $\mathrm{Ag} / \mathrm{C}$ nanoparticles, the obtained nanostructured latexes showed good stability post polymerization. Dispersion homogeneity is an indication of proper encapsulation; Tiarks et al. ${ }^{15}$ reported the effect of sonication on the encapsulation of carbon black in polystyrene latexes. They observed a wide density distribution of particles in dispersions of carbon black, when sonication was not applied, which indicated a deficient encapsulation; however, the application of sonication produced only one fraction of particles with narrow density distribution, indicating good encapsulation efficiency.

\section{Thermal Analysis}

Figure 4 shows DSC thermograms for neat PMMA and $\mathrm{Ag} / \mathrm{C}$ nanoparticle-PMMA nanocomposites with the three nanoparticle concentrations $(0.025,0.050,0.10 \mathrm{wt} \%)$. As can be seen $T_{\mathrm{g}}$ increased with the increment in nanoparticle concentration in respect to neat PMMA; however, it is worth saying that the increment in $T_{\mathrm{g}}$ for the nanoparticle load at $0.10 \mathrm{wt} \%$ was the same as for the load at $0.05 \mathrm{wt} \%\left(\sim 120^{\circ} \mathrm{C}\right)$. This behavior seems to be related to problems of nanoparticle dispersion and will be discussed in the DMA section.

When the polymer chains present strong interfacial affinity with the filler surface, a region of strongly bound polymer chains is formed. This region has been speculated to be within a few nanometers and called the "bound polymer layer"; ${ }^{16}$ at higher lengths, it has been called the "interaction zone." ${ }^{17}$ In this zone or region, the polymer chains exhibit a different behavior than that in the bulk; the strong packing hinders chain segmental mobility, which occurs under standard conditions at 


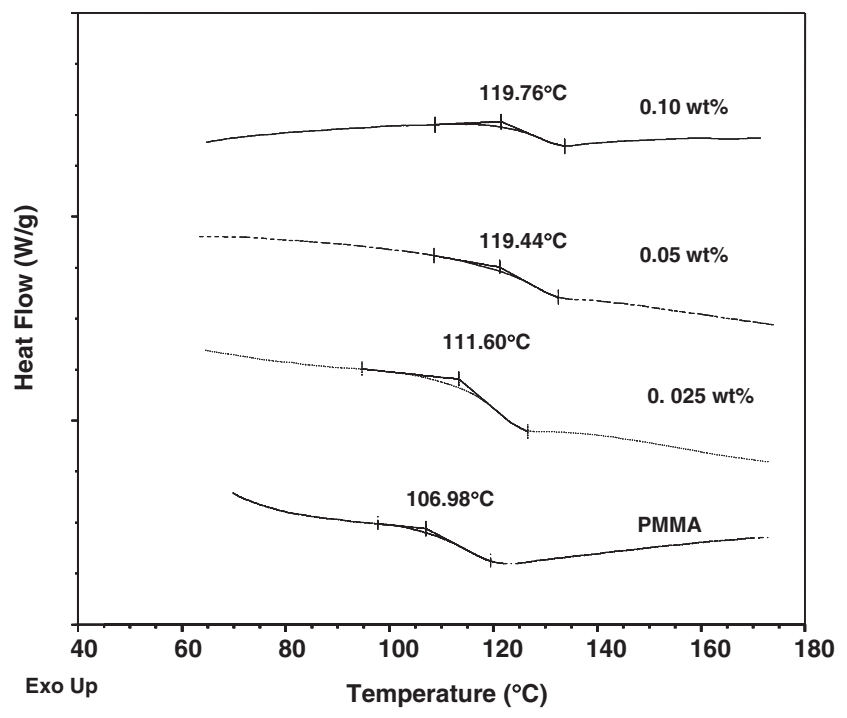

Figure 4. DSC thermograms for the neat PMMA and the $\mathrm{Ag} / \mathrm{C}$ nanoparticle-PMMA nanocomposites.

$T_{\mathrm{g}}$. Thus, more energy is required to allow the first thermal transitions, shifting $T_{\mathrm{g}}$ to a higher temperature. In the present case, the generation of a zone of highly restricted molecular mobility could be favored by the in situ polymerization because the monomer is always in intimate contact with the nanoparticles, promoting surface diffusion. Eventually, the growing chains at the monomer/particle interface are prone to attach strongly to the particle surface via mechanical adhesion or interlocking. From this result it was deduced that the cover layer of carbon onto the Ag nanoparticles worked as a good compatibilizer with the PMMA matrix; otherwise, a lowering in $T_{\mathrm{g}}$ would be observed instead of an increase. Indeed Ash et al. ${ }^{18}$ reported a reduction of $T_{\mathrm{g}}$ of $16^{\circ} \mathrm{C}$ for nanometric alumina/PMMA nanocomposites filled with $5 \mathrm{wt} \%$ of nanofiller; they suggested that the poor interfacial affinity of the nanocomposite produced large mobility in the polymer chains close to the nanoparticle surface, a lubrication effect, that in conjunction with an excellent nanoparticle dispersion produced the observed effect. Xu et al. ${ }^{19}$ in a similar context reported the reduction of PVC glass transition temperature, of some few centigrade degrees, in PVC/organo-montmorillonite nanocomposites.

\section{Mechanical Analysis}

It is worth saying DSC measurements are based only in thermal changes and nothing is said about mechanical consequences derived from these changes. Under this consideration, dynamical mechanical analysis (DMA) was used as a strong complementary technique to elucidate mechanical behavior associated to the reinforcement effect. Figure 5 reveals a discrete increase of elastic modulus, $E^{\prime}$, in the glassy region with the addition of $\mathrm{Ag} / \mathrm{C}$ nanoparticles. It is well known, on the one hand, that in this region molecular movements are highly restricted independently on the system morphology; therefore, filler effect is, in general, small. On the other hand, increment of

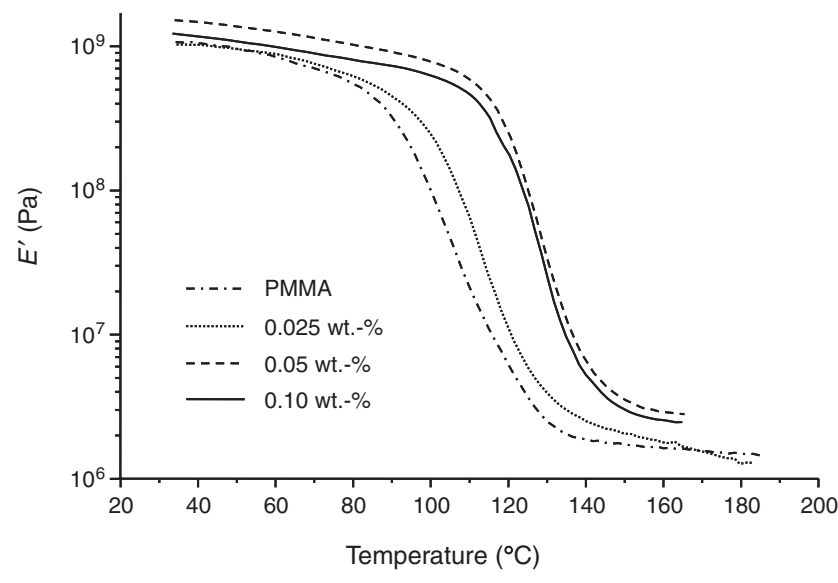

Figure 5. Elastic modulus, $E^{\prime}$, versus temperature $\left({ }^{\circ} \mathrm{C}\right)$ curves for the $\mathrm{Ag} / \mathrm{C}$ nanoparticle-PMMA nanocomposites with $0.025,0.05$ or $0.10 \mathrm{wt} \%$.

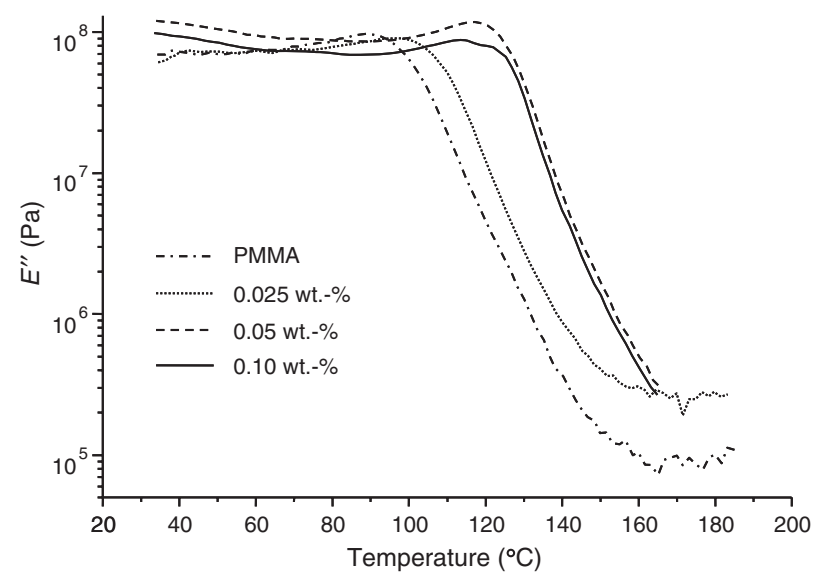

Figure 6. Loss modulus, $E^{\prime \prime}$, versus temperature $\left({ }^{\circ} \mathrm{C}\right)$ curves for the $\mathrm{Ag} / \mathrm{C}$ nanoparticle-PMMA nanocomposites with $0.025,0.05$ or 0.10 wt \%.

$E^{\prime}$ at the beginning of the rubbery plateau is more significant as the good interfacial interaction polymer/nanoparticle is responsible for the restriction of the great molecular mobility of the polymeric matrix, characteristic of this regime.

The analysis of Loss modulus, $E^{\prime \prime}$, (Figure 6) confirmed the $T_{\mathrm{g}}$ shifts to higher temperatures, as discussed in DSC characterization. According to the maxima in $E^{\prime \prime} T_{\mathrm{g}}$ of pure PMMA was $90^{\circ} \mathrm{C}$, whereas the nanocomposites with 0.025 , 0.050 and $0.10 \mathrm{wt} \%$ reached a transition temperature of 98,118 and $115^{\circ} \mathrm{C}$, respectively. Certainly, even though there was slight difference between the $T_{\mathrm{g}} \mathrm{s}$ obtained by DSC and DMA for the pure PMMA, the increments as a function of the $\mathrm{Ag} / \mathrm{C}$ nanoparticle concentration were by far important and more or less in the same proportion. Tan $\delta$ peaks, Figure 7, showed shifts of the maximum peaks of the nanocomposites at 0.025 , 0.05 or $0.10 \mathrm{wt} \%$ to higher temperatures, 118,134 and $132^{\circ} \mathrm{C}$, respectively, in respect to the neat PMMA $\left(110^{\circ} \mathrm{C}\right)$. Such a behavior has been reported by $\mathrm{Hu}$ et al. ${ }^{20}$ who observed shifts on $\tan \delta$ peak values to high temperature region of modified silica nanoparticles/PMMA nanocomposites; these shifts were 


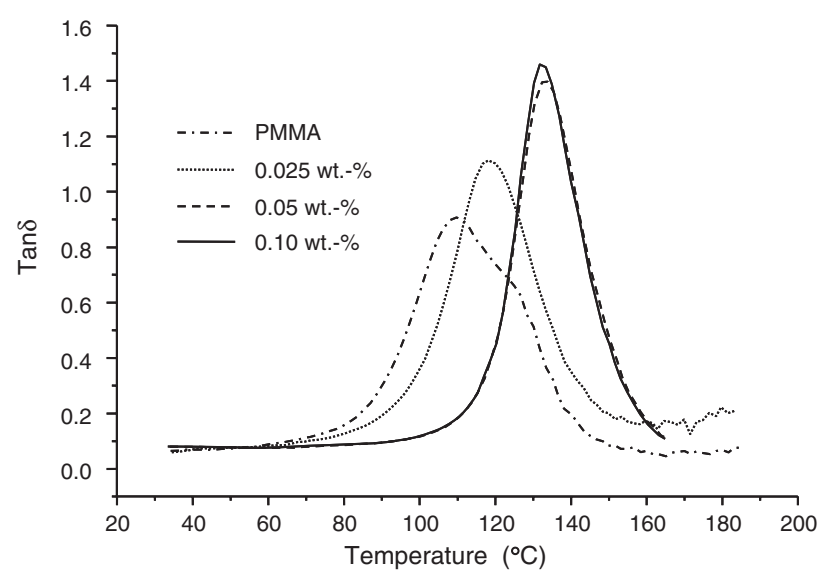

Figure 7. Tan $\delta$ versus temperature $\left({ }^{\circ} \mathrm{C}\right)$ curves for the $\mathrm{Ag} / \mathrm{C}$ nanoparticlePMMA nanocomposites with $0.025,0.05$ or 0.10 wt $\%$.

attributed to the high interaction between silica and PMMA matrix.

It is worth commenting that $\tan \delta$ gives a more general picture of the relative transition changes between evaluated samples; however, it is important to mention that these peaks must not be directly associated with $T_{\mathrm{g}}$, as often is erroneously done. $E^{\prime \prime}$ maximum is a more realistic measure of $T_{\mathrm{g}}$ because it represents the direct measure of a material property and, indeed, is closer in magnitude to DSC measurements, as suggested by Nielsen. ${ }^{21}$ It calls the attention that the nanocomposite at $0.10 \mathrm{wt} \%$ presented lower changes in both elastic and loss modulus, in respect to the composite with $0.05 \mathrm{wt} \%$ of nanoparticles. It is suggested that nanoparticle reaggregation in the composite with the highest nanoparticle load was more important than in the systems with 0.05 wt \% load. Concerning with this observation Thomas et al. ${ }^{22}$ reported DMA studies of pure polystyrene and calcium phosphate nanoparticle/PS composites. They observed basically the shift of $T_{\mathrm{g}}$ values to higher temperatures for the composites upto $5 \mathrm{wt} \%$. Such improvements were attributed to the better filler matrix interaction. However, at higher nanofiller loads ( 7 or $10 \mathrm{wt} \%)$ the composites showed negative shifts in respect to the virgin polymer. This anomalous behavior was related to progressive increment of nanofiller agglomeration, which reduced the better filler matrix interaction. In this respect, as observed in STEM pictures (Figure 2), nanoparticles dispersed mainly as aggregates and not as individual particles as it was expected; it should be taken into account that all the composites were synthesized under the same conditions, including surfactant concentration and time of sonication; therefore, nanoparticle reagglomeration during polymerization was more notable due to van der Waals forces. Thus, it could be suggested that increments in both surfactant concentration and time of sonication could improve nanoparticle dispersion and composite mechanical properties as a consequence. It has been reported in literature, that in the case of nanoclay reinforced composites, improvements in thermal stability and $T_{\mathrm{g}}$ are strongly related to high exfoliation degrees; ${ }^{23,24}$ however, dispersion seems not to influence only thermal properties but mechanical and rheological behavior too, as reported by Riva et al. ${ }^{25}$ who studied MMT/EVA microcomposites and nanocomposites; they found that dispersion is determining in composite mechanical properties.

Another very different scenario concerning the similarity of $T_{\mathrm{g}}$ shifts between samples at 0.05 and $0.1 \%$ wt $\%$ is provided by the theory of "rheological percolation," mentioned by Ramanathan et al. ${ }^{26}$ in their work about graphene polymer nanocomposites. The authors observed changes in $T_{\mathrm{g}}$ of about $30{ }^{\circ} \mathrm{C}$ in graphene/PMMA nanocomposites at only $0.05 \mathrm{wt} \%$, and no further $T_{\mathrm{g}}$ increments were found as graphene concentration was raised. They attribute this behavior to the generation of a substantial interphase zone because of a strong interaction or a percolated domain of altered intephase polymer, a morphological state called rheological percolation, which dramatically affects thermal and mechanical properties. In their work, based on the rheological percolation approach, the radius of influence of nanoparticles in the polymer surroundings was estimated from the particle size or surface area and the polymer radius of gyration as specific physical parameters affecting polymer chain dynamics. In the present work, the order in magnitude of $T_{\mathrm{g}}$ shifts and the almost reproducible $T_{\mathrm{g}}$ shifts for the samples at the higher concentrations aligns in good grade with an explanation based on this recent theory. As a matter of fact, unlikely the work by Ramanathan et al., results in the present paper includes an additional low nanoparticles concentration point $(0.025 \mathrm{wt} \%)$ that generates intermediates shifts magnitudes, which infers a progressive morphology of improved interphase properties. Upon this perspective, and according to the drastic results observed, if some agglomeration exists, this is not enough to avoid the formation of percolated altered domains, and also, it is suggested that further incorporation of nanoparticles will not change significantly the radius of influence of the interphase; however, increasing concentration eventually could lead to the predominance of agglomeration and consequent the dropping of properties. Certainly, a lot of work has to be done in order to deeply understand the implications of this new morphological focus.

In general, the common mechanism reported in literature for the enhancement of mechanical properties and dimensional stability of nanoclay composites, is the result from the achievement of a particular morphology: intercalated or exfoliated structures of the nanoclay. Whereas in the nanocomposites reported here, at this early stage there was no need to meet particular microestructural requirements in order to obtain such an equivalent change, at least in thermal stability or mechanical properties. An intense and continuous work; however, has to be made in this direction, because mechanisms responsible for the change in $T_{\mathrm{g}}$ are not completely clear at this time.

\section{CONCLUSIONS}

Miniemulsion polymerization was an effective method for $\mathrm{Ag} / \mathrm{C}$ nanoparticle encapsulation; however, nanoparticle reag- 
glomeration occurred at a certain extent because the encapsulation of nanoparticles by the polymer particles was not observed for individual nanoparticles but for aggregates. Therefore, slight modifications in surfactant concentration and time of sonication are needed to improve dispersion. In spite of this, DSC and DMA results showed an important $T_{\mathrm{g}}$ shift for PMMA to higher temperature, with only $0.050 \mathrm{wt} \%$ of $\mathrm{Ag} / \mathrm{C}$ nanoparticles, reflecting a high degree of polymer/ particle interaction, which promotes a high effective volume of filler. In practice, these results points out to polymer applications of high thermal and dimensional stability with minimal processing concerns.

Acknowledgment. Authors wish to thank Daniel Lardizabal, Miguel Orozco and Erika López for their helpful collaboration during this research.

Received: April 17, 2009

Accepted: June 14, 2009

Published: July 29, 2009

\section{REFERENCES}

1. A. Dufresne, J. Y. Cavaillé, and W. Helbert, Polym. Compos., 18, 198 (1997).

2. M. J. Wang, Rubber Chem. Technol., 71, 521 (1998).

3. C. Del Río, M. C. Ojeda, and J. L. Acosta, Eur. Polym. J., 36, 1687 (2000).

4. D. Ray, B. K. Sarkar, S. Das, and A. K. Rana, Compos. Sci. Technol., 62, 911 (2002).

5. R. Ibarra-Gómez, A. Márquez, O. S. Rodríguez-Fernández, and L. F. Ramos De Valle, Rubber Chem. Technol., 76, 969 (2003).

6. M. Okamoto, S. Morita, H. Taguchi, Y. H. Kim, T. Kotaka, and H. Tateyama, Polymer, 41, 3887 (2000).

7. X. Qu, T. Guan, G. Liu, Q. She, and L. Zhang, J. Appl. Polym. Sci., 97, 348 (2005).
8. M. A. López Manchado, L. Valentini, J. Biagiotti, and J. M. Kenny, Carbon, 43, 1499 (2005).

9. F. Gong, M. Feng, C. Zhao, S. Zhang, and M. Yang, Polym. Degrad. Stab., 84, 289 (2004).

10. E. A. Zaragoza-Contreras, E. D. Lozano-Rodríguez, M. RománAguirre, W. Antunez-Flores, C. A. Hernández-Escobar, S. G. FloresGallardo, and A. Aguilar-Elguezabal, Micron, 40, 621 (2009).

11. M. S. El-Aasser, C. D. Lack, J. W. Vanderhoff, and F. M. Fowers, Colloids Surf., 29, 103 (1988).

12. P. J. Blythe, B. R. Morrison, K. A. Mathauer, E. D. Sudol, and M. S. El-Aasser, Macromolecules, 32, 6944 (1999).

13. K. Ouzineb, C. Graillat, and T. F. McKenna, J. Appl. Polym. Sci., 91, 115 (2004).

14. K. Landfester, Macromol. Symp., 150, 171 (2000).

15. F. Tiarks, K. Landfester, and M. Antonietti, Macromol. Chem. Phys., 202, 51 (2001).

16. P. Cousin and P. Smith, J. Polym. Sci., Part B: Polym. Phys., 32, 459 (1994).

17. B. J. Ash, D. F. Rogers, C. J. Wiegand, L. S. Schadler, R. W. Siegel, and B. C. Benicewicz, Appl. Polym. Compos., 23, 1014 (2002).

18. B. J. Ash, L. S. Schadler, and R. W. Siegel, Mater. Lett., 55, 83 (2002).

19. W. Xu, M. Ge, and W.-P. Pan, J. Therm. Anal. Calorim., 78, 91 (2004).

20. Y.-H. Hu, C.-Y. Chen, and C.-C. Wang, Polym. Degrad. Stab., 84 545 (2004).

21. L. Nielsen and R. F. Landel, in "Mechanical Properties of Polymers and Composites," Elsevier, New York, 1991.

22. P. S. Thomas, S. Thomas, S. Bandyopadhyay, A. Wurmd, and C. Schick, Compos. Sci. Technol., 68, 3220 (2008).

23. A. Leszczyńska, J. Njuguna, K. Pielichowski, and J. R. Banerjee, Thermochim. Acta., 453, 75 (2007).

24. A. Leszczyńska and K. Pielichowski, J. Therm. Anal. Calorim., 93, 677 (2008).

25. A. Riva, M. Zanetti, M. Braglia, G. Camino, and L. Falqui, Polym. Degrad. Stab., 77, 299 (2002).

26. T. Ramanathan, A. A. Abdala, S. Stankovich, D. A. Dikin, M. Herrera Alonso, R. D. Piner, D. H. Adamson, H. C. Schniepp, X. Chen, R. S Ruoff, S. T. Nguyen, I. A. Aksay, R. K. Prud'homme, and L. C. Brinson, Nat. Nanotechnol., 3, 327 (2008). 